\title{
CCD PHOTOMETRY OF THE M 67 CLUSTER IN THE VILNIUS PHOTOMETRIC
} SYSTEM

\author{
R. Boyle, \\ Vatican Observatory Group, Steward Observatory \\ V. Straižys, \\ Institute of Theoretical Physics and Astronomy, Vilnius \\ F. Vrba, \\ U.S. Naval Observatory Flagstaff Station \\ F. Smriglio and A. K. Dasgupta \\ Istituto Astronomico, Universita La Sapienza
}

The Vilnius photometric system, consisting of seven passbands at 345, 374, 405, 466, 516, 544 and $656 \mathrm{~nm}$ makes it possible to determine spectral classes (or temperatures), absolute magnitudes (or surface gravities), metallicities and peculiarity types for stars of all spectral types in the presence of interstellar reddening (Straižys 1977, 1992a,b). This makes the system very useful for the determination of the physical parameters of stars which are too faint to be studied by spectroscopic methods. The system is especially effective when used with CCD detectors which combine a wide field, high sensitivity and high photometric accuracy.

For the first time, the Vilnius photometric system was successfully used with a CCD detector in 1986 and 1987 on the 90-cm telescope of the Kitt Peak National Observatory (Boyle et al. 1990a, b, 1992, Smriglio et al. 1991). It was shown that CCD Vilnius photometry allows one to obtain two-dimensional classification of stars down to $17^{\text {th }}$ mag with exposures of the order of about $20 \mathrm{~min}$ for two ultraviolet filters and about $5 \mathrm{~min}$ for other five filters.

However, the number of stars in a $5^{\prime} \times 7^{\prime}$ area down to $17^{\text {th }}$ mag is insufficient for the statistical investigation of stellar populations. CCD chips with 2048 x 2048 pixels offer a possibility to increase the field size and the number of stars considerably. An especially large field (23' x 23') can be obtained with the CCD camera operating on the 1-meter Ritchey telescope of the Flagstaff Station of the US Naval Observatory. We decided to test a possibility of using this camera for photometry of stars in the Vilnius system. For this, the field of the open cluster M 67 was chosen.

The cluster area was observed on two nights, February 18/19 and March 25/26, 1993. The exposure lengths were: $15 \mathrm{~min}$ for $\mathrm{U}$ and $\mathrm{P}, 5 \mathrm{~min}$ for $\mathrm{X}, \mathrm{Y}$ and $\mathrm{V}$ and $3 \mathrm{~min}$ for $\mathrm{Z}$ and $\mathrm{S}$. The filters give an unvignetted field of $20^{\prime}$ diameter. The standard routines of the IRAF software 
package were used in the reductions.

For transformation of the instrumental CCD magnitudes and color indices to the standard Vilnius system we have used five standard stars in M 67 measured photoelectrically. The average magnitudes $\mathrm{V}$ and color indices (U-V), (P-V), (X-V), (Y-V), (Z-V) and (V-S) for 338 stars brighter than $\mathrm{V}=14^{\text {th }} \mathrm{mag}$ were obtained. From an intercomparison of the February and March observations we estimate that their accuracy is of the order of $\pm 0.02 \mathrm{mag}$.

A CM diagram V, (Y-V), has been constructed for $\mathrm{M} 67$ stars down to $\mathrm{V}=14^{\text {th }}$ mag. The index $(\mathrm{Y}-\mathrm{Y})$ is one of the best temperature indicators in the Vilnius system and is very close to (b-y) of the Strömgren system. The zero-age main sequence, adjusted to the true distance modulus $\mathrm{V}-\mathrm{M}(\mathrm{V})=9.6$ and color excess $\mathrm{E}(\mathrm{B}-\mathrm{V})=0.05$, the expected values for $\mathrm{M} 67$, is shown. This diagram is not very different from the $\mathrm{V},(\mathrm{B}-\mathrm{V})$ diagram of the UBV system (see Montgomery et al. 1993). The photometric data have also been used to classify the stars in spectral and luminosity classes by using several methods developed at the Vilnius Observatory and at the Rome Astronomical Institute.

The CCD photometry of the cluster M 67 in the Vilnius system shows that even with short exposures of the order of $15 \mathrm{~min}$ for ultraviolet filters and 3 - $5 \mathrm{~min}$ for other filters useful photometric results can be obtained. Several hours of CCD observations replace tens of nights of usual photoelectric photometry. The results obtained for M 67 combined with the future CCD photometry of other open and globular clusters will form a data-base for the calibration of two-color and reddening-free diagrams of the Vilnius system in terms of evolutionary tracks and ages.

\section{REFERENCES}

Boyle, R. P., Smriglio, F., Nandy, K. and Straižys, V. 1990a A\&AS 84, 1

Boyle, R. P., Smriglio, F., Nandy, K. and Straižys, V. 1990b A\&AS 86, 395

Boyle R. P., Dasgupta A. K., Smriglio F., Straižys V. and Nandy K. 1992 A\&AS 95, 51

Montgomery, K. A., Marschall, L. A. and Janes, K. A. 1993 AJ

Smriglio, F., Nandy, K., Boyle, R. P., Dasgupta, A. K., Straižys, V. and Janulis R. 1991 A\&AS 88,87

Straižys, V. 1977 Multicolor Stellar Photometry, Mokslas Publishers, Vilnius

Straižys, V. 1992a Multicolor Stellar Photometry, Pachart Publ. House, Tucson, Arizona

Straižys, V. 1992b Baltic Astronomy, 1, 107 